\title{
An Improved Route for the Synthesis of Guanine Quadruplex Ligand Phen-DC3
}

\author{
Caitlin E. Miron ${ }^{a}$ \\ Anne Petitjean*a \\ a Department of Chemistry, Queen's University \\ 90 Bader Lane, Kingston, ON, Canada K7L3N6 \\ * indicates the main/corresponding author.
}

anne.petitjean@chem.queensu.ca
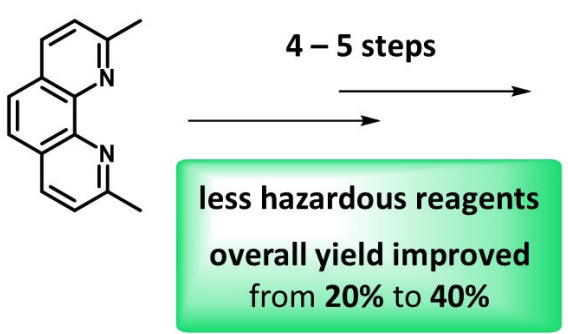

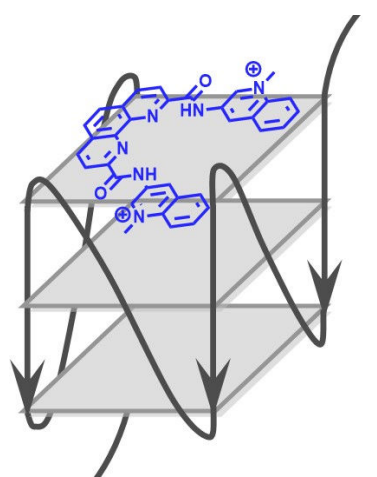

\begin{abstract}
Received:
Accepted:
Accepted:
Published online:

POblis

Abstract The recognition of non-canonical DNA and RNA architectures such as guanine quadruplexes by small molecule ligands has become a promising strategy for anticancer and antiviral applications in recent years, leading to an exponential increase in the number of quadruplex ligands reported in the literature. There is consequently a need for "benchmark" compounds which can be used as controls to facilitate comparisons between novel and previously reported ligands. One candidate for this role is Phen-DC3, which binds with high affinity and selectivity to guanine quadruplexes. To encourage its use in this role, an alternate synthetic route for the production of PhenDC3 that may be more appropriate for implementation on a large scale is reported. This pathway eliminates the need for several hazardous reagents and increases the overall synthetic yield from $21 \%$ to a maximum of $43 \%$.
\end{abstract}

The selective recognition of biologically relevant oligonucleotide architectures by small molecules has become an attractive strategy in recent years for anticancer ${ }^{1}$ and antiviral ${ }^{2}$ applications. One such architecture, the guanine quadruplex (G4), has been observed to form in transiently single-stranded guanine-rich DNA or RNA sequences through the cationstabilized $\pi-\pi$ stacking of guanine tetrads, each composed of four guanines interacting through Hoogsteen-type hydrogen bonding (Fig. 1a). ${ }^{3}$ The prevalence of G4-forming sequences in the promoter region of oncogenes as well as in telomeric DNA supports the exploration of G4s as targets for anticancer therapeutics. The stabilization of these architectures by small molecule ligands can down-regulate oncogene expression, ${ }^{1 \mathrm{~b}}$ decrease telomerase activity (thus potentially limiting the infinite proliferative ability of $85 \%$ of cancer cells where telomerase is active), ${ }^{1 \mathrm{~d}, 4}$ induce cell death, ${ }^{1 \mathrm{c}}$ and interfere with DNA damage repair mechanisms in cancer cells, making radiation therapy more effective. 5 The presence of G4-forming sequences in the genomes of viruses such as HIV suggests that ligand-induced stabilization of DNA and/or RNA G4s may also prove useful in antiviral therapeutics. ${ }^{6}$
In recognition of this potential, the number of ligands developed to selectively recognize DNA and RNA G4s is growing rapidly. There is therefore a pressing need for "benchmark" ligands that can be used as controls in biophysical and biochemical studies in order to ensure that variations in experimental conditions do not prevent reliable comparisons to literature results. Ideally, such a ligand would exhibit both high affinity binding to G4 and excellent selectivity for G4 over duplex architectures, so that it can be widely used. One ligand which fulfils these criteria is Phen-DC3, a bis-quinolinium compound developed by TeuladeFichou and coworkers. ${ }^{7}$

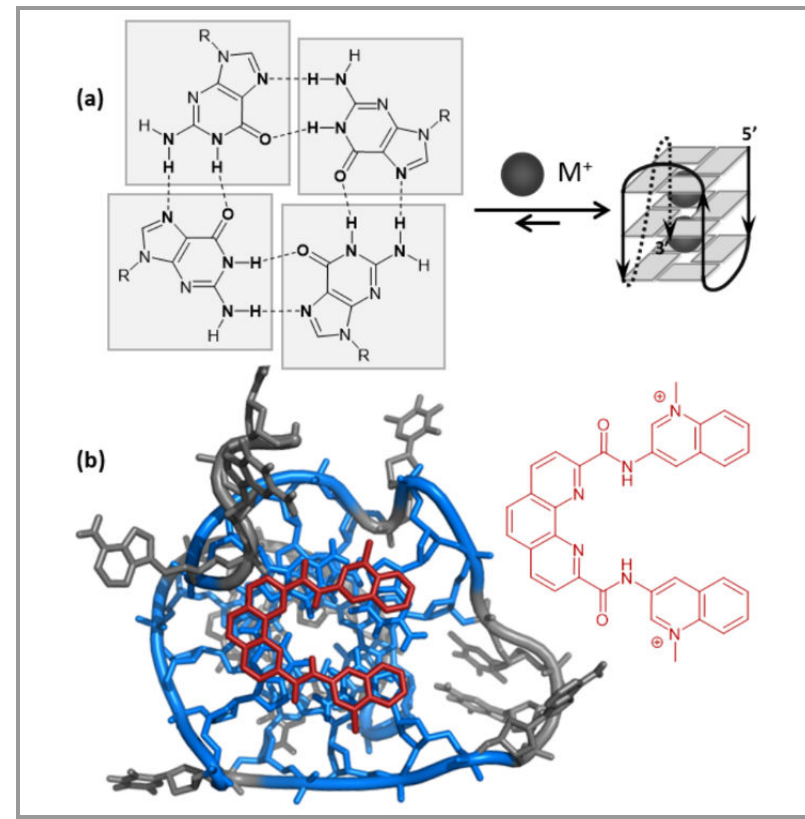

Figure 1 (a) Guanine tetrads stack into a G4 (hybrid topology shown here) in the presence of cations. ${ }^{3}$ (b) Top view of the complex formed between PhenDC3 (red, counter-ions omitted) and the C-MYC G4 shows extensive $\pi-\pi$ stacking between guanine tetrads (blue) and the ligand (PDB ID 2MGN). 7,8 
These features are imparted by the extensive overlap of the ligand's $\pi$ system with that of the quadruplex's terminal guanine tetrads, as can be seen in the NMR structure of Phen-DC3 bound to a $\mathrm{G} 4$ formed in the $C-M Y C$ oncogene promoter region (Fig. 1b). ${ }^{8 a}$ The extensive literature available on biophysical and cellbased studies of the interactions of Phen-DC3 with G4s makes this ligand an attractive point of comparison for novel G4 ligands. ${ }^{6 c-d, 7,8 a, 9}$ Unfortunately, the feasibility of this application is currently limited due to the significant expense of milligram quantities of commercially available Phen-DC3.

We therefore decided that it was worth revisiting the synthesis of the ligand in order to (i) improve the overall yield of synthesis and (ii) where possible, avoid the use of reagents that may preclude synthesis on a large scale due to safety considerations. To this end, we describe in this letter a four to five step alternate route for the synthesis of Phen-DC3 that eliminates the need for three hazardous and/or toxic reagents and increases the overall yield from $21 \%$ to $36-43 \%$.

The original synthesis of Phen-DC3 (see first three steps in Scheme 1a) involved a four step pathway starting from commercially available neocuproine (2,9-dimethyl-1,10phenanthroline). ${ }^{7}$ While developing an alternate synthetic route for the bis-quinolinium compound (Scheme 2), we decided to exclude selenium dioxide as an oxidizing agent due to its toxicity and concerns that traces of selenium might remain present but undetected in the aldehyde derivative $\mathbf{1}$, where purity was to be primarily assessed by comparison of experimental and literature NMR data. It is also worth noting that the scope of the selenium dioxide-mediated oxidation is limited and does not proceed when electron-withdrawing substituents are present at the 4 and 7 positions of the phenanthroline unit. ${ }^{10}$ Attempts to obtain compound 3 directly from neocuproine via oxidation with $\mathrm{CrO}_{3}$ or $\mathrm{KMnO}_{4}$ resulted in the formation of byproducts such as 5,6-dihydro-5,6-dioxo-1,10-phenanthroline-2,9dicarboxylic acid and failed to generate $\mathbf{3}$ in any significant yield. ${ }^{11}$ As an alternative strategy, neocuproine and its 4,7substituted derivatives can also readily undergo radical chlorination to compound $\mathbf{2}$ in the presence of $\mathrm{N}$ chlorosuccinimide (NCS). ${ }^{12}$ Early reports of this reaction involved the use of carbon tetrachloride as a solvent, which was undesirable given its detrimental environmental impact and known health hazards. ${ }^{13}$ Fortunately, the reaction also proceeds in commercially available chloroform or chloroform/dichloromethane mixtures. Although the use of free radical initiators such as $m$-chloroperoxybenzoic acid ${ }^{12 b}$ and the in situ generation of a more reactive halogenating agent by reaction of NCS with triphenylphosphine ${ }^{12 c}$ were briefly investigated, in our hands the NCS-promoted conversion to 2 proceeded equally well in the absence of such additives, provided that the procedure was followed under inert atmosphere. Reactions run in the presence of air afforded complex mixtures. ${ }^{12 \mathrm{~d}}$ The optimized reaction was consequently run in chloroform with slight stoichiometric excess of NCS under an argon gas atmosphere, giving a $68 \%$ yield of compound 2 after purification by column chromatography. ${ }^{21,22}$ Subsequent hydrolysis of $\mathbf{2}$ in sulfuric acid ${ }^{10}$ afforded pure dicarboxylic acid $\mathbf{3}$ in quantitative yields (Scheme 1b). ${ }^{23}$

In a subsequent step of the original synthetic route, the explosive nature of peptide coupling reagent 1-hydroxy-7azabenzotriazole (HOAt) represents a significant hazard and may have posed an issue for implementing synthesis on a large scale. ${ }^{14}$ The sale of HOAt has also been discontinued by many commercial suppliers, possibly for this reason, thus limiting its use even on a smaller scale. We therefore proposed an alternative peptide coupling methodology involving $\mathrm{N}$-(3dimethylaminopropyl)- $N$-ethylcarbodiimide hydrochloride $(\mathrm{EDC} \bullet \mathrm{HCl}$ ) and 4-dimethylaminopyridine (DMAP), which serves as both a base and an activator for the carbodiimide coupling. Peptide coupling using EDC has been reported to proceed in basic aqueous media, ${ }^{15}$ suggesting that on a large scale anhydrous conditions may not in fact be necessary. Using this methodology to couple $\mathbf{3}$ with commercially available 3aminoquinoline, pure compound $\mathbf{4}$ was isolated by filtration in yields similar to that reported by Teulade-Fichou et al. ${ }^{7}$ At this stage, our alternate synthetic route offers an improvement in yield from the reported $41 \%$ to $58 \%{ }^{24}$

Finally, the use of methyl trifluoromethanesulfonate (triflate) as methylating agent is admittedly ideal for the purposes of generating Phen-DC3 as a triflate salt (Scheme 2a).

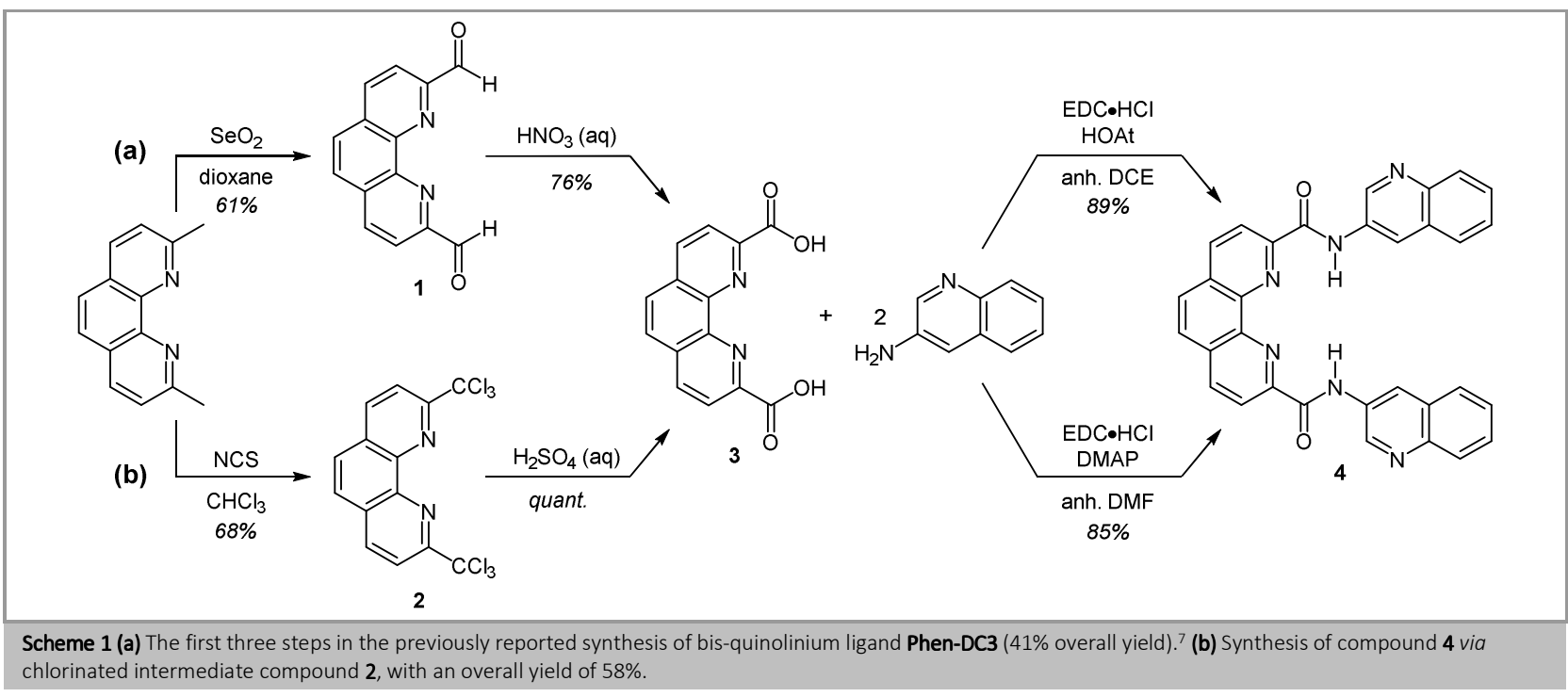




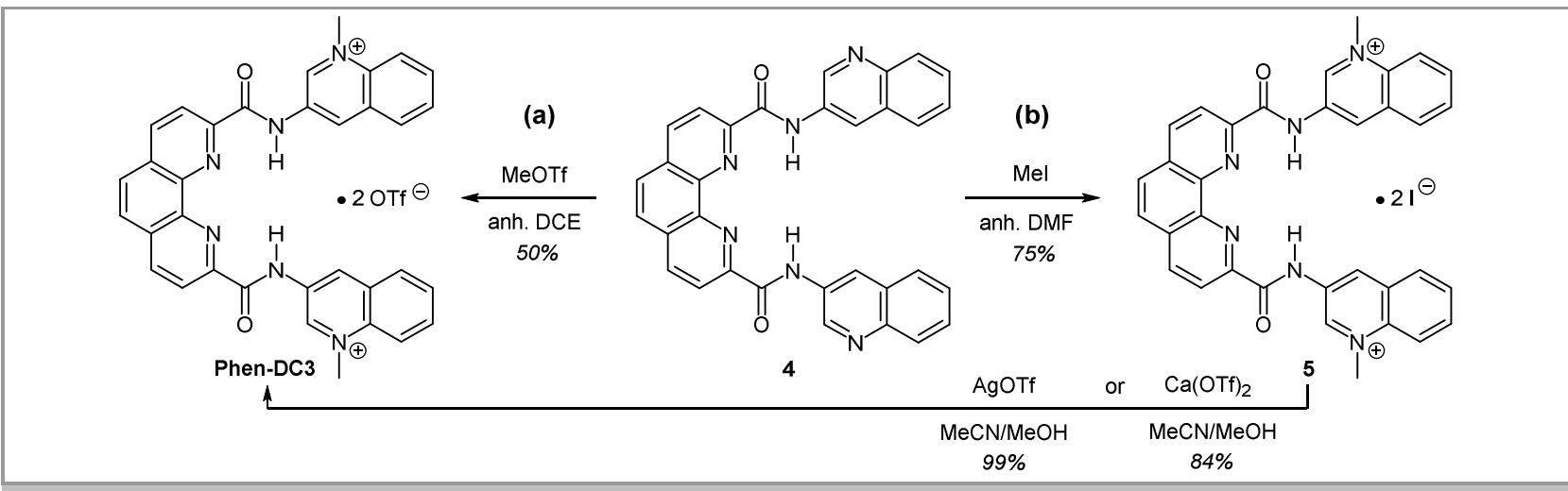

Scheme 2 Synthesis of Phen-DC3 via (a) the reported methylation of compound $\mathbf{4}$ using methyl triflate, ${ }^{7}$ and (b) the proposed alternate strategy involving the use of methyl iodide as methylating agent, which affords the diiode salt in good yield, followed by metathesis in cases where exchange of counter-ions is necessary.

Unfortunately, as a strong alkylating agent, methyl triflate is highly carcinogenic, reacts in a highly exothermic manner to the presence of amine reagents, must be handled under anhydrous, inert atmospheric conditions, and degrades if stored for long periods of time - all of which become disadvantages for large scale synthesis. ${ }^{16}$ Adopting a different methylating agent at this stage of the synthesis would evidently require an additional step in which the quinolinum counter-ions are exchanged for triflate anions (Scheme 2b).

It should be noted, however, that the formulation of Phen-DC3 as a triflate salt may not be required. The iodide salts of the ligand and its derivatives have in fact been sufficient for several studies on guanine quadruplex recognition. ${ }^{17}$ The use of the iodide salt for cell-based imaging certainly suggests that the triflate anion is not required for biological studies. ${ }^{17 \mathrm{~b}}$ As an alternative to methyl triflate, the reduced reactivity of methyl iodide ${ }^{16}$ as alkylating agent eliminates the issue of cross-reactivity that prevents the use of solvents such as anhydrous DMF. In our hands, DMF has proven to be much more effective in solubilizing compound $\mathbf{4}$ than methyl triflate-compatible DCE, leading to a cleaner conversion to the methylated product. Consequently, Phen-DC3 formulated as diiodide salt $\mathbf{5}$ can be isolated cleanly by simple filtration with significantly improved yields. ${ }^{25}$

Following this, we have explored two metathesis methods to exchange iodide for triflate counter-ions. The more common approach involves isolating the desired product from methanol after addition of stoichiometric quantities of silver(I) triflate and removal of precipitated silver iodide. ${ }^{18,26}$ Although this method does afford pure product in near-quantitative yields, it could be argued that the use of an expensive and cytotoxic transition metal in the last step of synthesis for a compound that may be used in cell-based studies is not ideal. ${ }^{19 a}$ Silver(I) ions have also been reported to disrupt the structure of guanine quadruplexes through coordination to guanine residues. ${ }^{19 b}$ Should this pose a concern, Phen-DC3 can also be obtained in good yield as a triflate salt via metathesis with the more biocompatible and affordable calcium(II) triflate. ${ }^{20,26}$ Quantitative ${ }^{19} \mathrm{~F} \quad$ NMR using trifluorotoluene as an internal standard was used in both cases to confirm complete conversion to the triflate salt.

In summary, we have developed an alternate pathway through which Phen-DC3 can be produced as an iodide salt in $43 \%$ yield, or as the commercially available triflate salt in $36-43 \%$ yield. This represents a significant improvement in comparison to the $21 \%$ overall yield reported in the previous synthesis of Phen-DC3. ${ }^{7}$ The alternate synthetic route, which eliminates the need for three explosive, toxic, or carcinogenic reagents, should allow research laboratories to more readily implement large scale syntheses of Phen-DC3, thereby enabling its widespread use as a benchmark compound against which novel G4 ligands can be compared.

\section{Funding Information}

Funding from the Natural Sciences and Engineering Research Council (NSERC-DG, grant number 315311-2013; NSERC PGS-D), the Canada Foundation for Innovation, and Queen's University is acknowledged.

\section{Supporting Information}

YES (this text will be updated with links prior to publication)

\section{Primary Data}

NO (this text will be deleted prior to publication)

\section{References and Notes}

(1) (a) Neidle, S. J. Med. Chem. 2016, 59, 5987. (b) Brooks, T. A.; Kendrick, S.; Hurley, L. FEBS J. 2010, 277, 3459. (c) Müller, S.; Rodriguez, R. Expert Rev. Clin. Pharmacol. 2014, 7, 663. (d) Patel, D. J.; Phan, A. T.; Kuryavyi, V. Nucleic Acids Res. 2007, 35, 7429.

(2) Harris, L. M.; Merrick, C. J. PLoS Pathog. 2015, 11, e1004562.

(3) (a) Huppert, J. L. Chem. Soc. Rev. 2008, 37, 1375. (b) Burge, S.; Parkinson, G. N.; Hazel, P.; Todd, A. K.; Neidle, S. Nucleic Acids Res. 2006, 34, 5402.

(4) Kim, N. W.; Piatyszek, M. A.; Prowse, K. R.; Harley, C. B.; West, M. D.; Ho, P. L. C.; Coviello, G. M.; Wright, W. E.; Weinrich, S. L.; Shay, J. W. Science 1994, 266, 2011.

(5) Merle, P.; Evrard, B.; Petitjean, A.; Lehn, J.-M.; Teulade-Fichou, M.P.; Chautard, E.; De Cian, A.; Guittat, L.; Tran, P. L. T.; Mergny, J.-L.; Verrelle, P.; Tchirkov, A. Mol. Cancer Ther. 2011, 10, 1784.

(6) (a) Perrone, R.; Nadai, M.; Frasson, I.; Poe, J. A.; Butovskaya, E.; Smithgall, T. E.; Palumbo, M.; Palù, G.; Richter, S. N. J. Med. Chem. 2013, 56, 6521. (b) Amrane, S.; Kerkour, A.; Bedrat, A.; Vialet, B.; Andreola, M.-L.; Mergny, J.-L. J. Am. Chem. Soc. 2014, 136, 5249. (c) Lista, M. J.; Martins, R. P.; Billant, O.; Contesse, M.-A.; Findakly, S.; Pochard, P.; Daskalogianni, C.; Beauvineau, C.; Guetta, C.; Jamin, C.; Teulade-Fichou, M.-P.; Fåhraeus, R.; Voisset, C.; Blondel, M. Nature Commun. 2017, 8, 16043. (d) Madireddy, A.; Purushothaman, P.; Loosbroock, C. P.; Robertson, E. S.; Schildkraut, C. L.; Verma, S. C. Nucleic Acids Res. 2016, 44, 3675. (e) Biswas, B.; Kandpal, M.; Jauhari, U. K.; Vivekanandan, P. BMC Genomics 2016, 17, 949. (f) Fleming, A. M.; Ding, Y.; Alenko, A.; Burrows, C. J. ACS Infect. Dis. 2016, 2, 674 . 
(7) De Cian, A.; DeLemos, E.; Mergny, J.-L.; Teulade-Fichou, M.-P.; Monchaud, D. J. Am. Chem. Soc. 2007, 129, 1856.

(8) (a) Chung, W. J.; Heddi, B.; Hamon, F.; Teulade-Fichou, M.-P.; Phan, A. T. Angew. Chem. Int. Ed. 2014, 53, 999. (b) Quadruplex graphic generated using the PyMOL Molecular Graphics System, version 1.3, Schröedinger.

(9) (a) De Rache, A.; Mergny, J.-L. Biochimie 2015, 115, 194. (b) Monchaud, D.; Allain, C.; Bertrand, H.; Smargiasso, N.; Rosu, F.; Gabelica, V.; De Cian, A.; Mergny, J.-L.; Teulade-Fichou, M.-P. Biochimie 2008, 90, 1207. (c) Bončina, M.; Hamon, F.; Islam, B.; Teulade-Fichou, M.-P.; Vesnaver, G.; Haider, S.; Lah, J. Biophys. J. 2015, 108, 2903. (d) Lacroix, L.; Séosse, A.; Mergny, J.-L. Nucleic Acids Res. 2011, 39, e21. (e) Guilbaud, G.; Murat, P.; Recolin, B.; Campbell, B. C.; Maiter, A.; Sale, J. E.; Balasubramanian, S. Nature Chem. 2017, 9, 1110. (f) Gomez, D.; Guédin, A.; Mergny, J.-L.; Salles, B.; Riou, J.-F.; Teulade-Fichou, M.-P.; Calsou, P. Nucleic Acids Res. 2010, 38, 7187.

(10) Larsen, A. F.; Ulven, T. Org. Lett. 2011, 13, 3546.

(11) (a) Albrecht, M. Chem. Eur J. 2000, 6, 3485. (b) Qi, H.; Teesdale, J. J.; Pupillo, R. C.; Rosenthal, J.; Bard, A. J. J. Am. Chem. Soc. 2013, 135, 13558. (c) Jun, L.; Zheng, M.; Li, W.; Wang, H.; Zhang, H.; Wu, H.; Jia, Z.; Zheng, L.; Tian, J. CN102040608, 2011. (d) Qi, D.; Wang, X. CN105884683, 2014.

(12) (a) Beer, R. H.; Jimenez, J.; Drago, R. S. J. Org. Chem. 1993, 58, 1746. (b) Lamarque, L.; Bazin, H.; Blanche, E. PCT Int. Appl. WO 2010070232, 2010. (c) Goswami, S.; Maity, A. C.; Fun, H.-K. Chem. Lett. 2007, 36, 552. (d) This observation is consistent with oxygen acting as both oxidant and radical scavenger, thereby impeding progress along the chlorinating radical reaction pathway (see Anderson, A. G.; Tober, T. Y. J. Org. Chem. 1980, 45, 1695).

(13) Holbrook, M. T. Carbon tetrachloride. In Kirk-Othmer Encyclopedia of Chemical Technology; John Wiley \& Sons, 2000, 1.

(14) Wehrstedt, K. D.; Wandrey, P. A.; Heitkamp, D. J. Hazard Mater. 2005, 126, 1 .

(15) (a) Montalbetti, C. A. G. N.; Falque, V. Tetretrahedron 2005, 61, 10827. (b) Nakajima, N.; Ikada, Y. Bioconjugate Chem. 1995, 6, 123.

(16) Alder, R. W.; Phillips, J. G. E.; Huang, L.; Huang, X. Methyl trifluoromethanesulfonate. In Encyclopedia of Reagents for Organic Synthesis; John Wiley \& Sons: 2005, 1.

(17) (a) Larsen, A. F.; Nielsen, M. C.; Ulven, T. Chem. Eur. J. 2012, 18, 10892. (b) Lefebvre, J.; Guetta, C.; Poyer, F.; Mahuteau-Betzer, F.; Teulade-Fichou, M.-P. Angew. Chem. Int. Ed. 2017, 56, 11365.

(18) Dorazco-González, A.; Höpfl, H.; Medrano, F.; Yatsimirsky, A. K. J. Org. Chem. 2010, 75, 2259.

(19) (a) Kim, S.; Choi, J. E.; Choi, J.; Chung, K.-H.; Park, K.; Yi, J.; Ruy, D.-Y. Toxicol. In Vitro 2009, 23, 1076. (b) Zhou, X.-H.; Kong, D.-M.; Shen, H.-X. Anal. Chem. 2010, 82, 789.

(20) Adapted from Gries, W.-K.; Günther, E.; Hünig, S. Liebigs Ann. Chem. 1991, 1021.

(21) Experimental. Commercially available compounds were used as received. Reagents for reactions requiring anhydrous conditions were pre-dried under vacuum and $\mathrm{P}_{2} \mathrm{O}_{5}$. Column chromatography was performed with Silica-P flash silica gel (40-63 $\mu \mathrm{m}$ particle size, $60 \AA$ A pore diameter). NMR data was obtained with $300 \mathrm{MHz}, 400$ $\mathrm{MHz}$ and $500 \mathrm{MHz}$ Bruker instruments at $25{ }^{\circ} \mathrm{C} . \mathrm{CDCl}_{3}$ was neutralized before use by passing through a short column of basic alumina. Peak listings for all spectra are given in ppm and referenced against the signal of the residual solvent signal $\left({ }^{1} \mathrm{H}\right.$ $\mathrm{NMR}$ ) or internal standard ( $\left.{ }^{19} \mathrm{~F} \mathrm{NMR}\right)$.

(22) 2,9-Bis(trichloromethyl)-1,10-phenanthroline (2). To a solution of 2,9-dimethyl-1,10-phenanthroline (430 mg, $2.1 \mathrm{mmol}$, 1.0 equiv.) in chloroform ( $17 \mathrm{~mL})$ under argon atmosphere at room temperature was added dropwise a solution of $\mathrm{N}$ chlorosuccinimide (NCS, $2.2 \mathrm{~g}, 0.017 \mathrm{~mol}, 8.0$ equiv.) in chloroform $(72 \mathrm{~mL})$. The reaction mixture was protected from light while stirring and heating under reflux ( 6 hours). The reaction mixture was then cooled to $4^{\circ} \mathrm{C}$ and filtered. The filtrate was concentrated under reduced pressure to yield the crude product. Purification by column chromatography using gradient $\mathrm{CHCl}_{3}$ :hexanes (1:1 to 2:1) afforded pure compound 2 (590 mg, 68\%). $\mathrm{CH}_{2} \mathrm{Cl}_{2}$ :hexanes was also tested as eluent but gave a slightly poorer separation by TLC. ${ }^{1} \mathbf{H}$ NMR (400 MHz, $\left.\mathrm{CDCl}_{3}\right) \delta 7.96(\mathrm{~s}, 2 \mathrm{H}), 8.32\left(\mathrm{~d},{ }^{3} \mathrm{~J}=8 \mathrm{~Hz}, 2 \mathrm{H}\right)$, $8.44(\mathrm{~d}, 3 \mathrm{~J}=8 \mathrm{~Hz}, 2 \mathrm{H})$. R.f. $\left(1: 1 \mathrm{CHCl}_{3}\right.$ :hexanes $)=0.26$. M.p. $227^{\circ} \mathrm{C}$ (lit. $\left.225-227^{\circ} \mathrm{C}\right) .{ }^{11 \mathrm{c}}$

(23) 1,10-Phenanthroline-2,9-dicarboxylic acid (3). A solution of 2 (540 mg, $1.3 \mathrm{mmol}, 1.0$ equiv.) in concentrated aqueous sulfuric acid $(95-98 \%, 17 \mathrm{~mL})$ was stirred at $85^{\circ} \mathrm{C}$ for 7 hours. Following this, the brown solution was cooled to room temperature and poured over crushed ice. The ice was allowed to melt and the resulting white suspension filtered under vacuum, washed with water, and air-dried to afford pure compound 3 (360 mg quantitative yield). ${ }^{1} \mathbf{H}$ NMR (300 MHz, DMSO-d 6 ) $\delta 8.22(\mathrm{~s}, 2 \mathrm{H}$ ), $8.42(\mathrm{~d}, 3 \mathrm{~J}=8.4 \mathrm{~Hz}, 2 \mathrm{H}), 8.74\left(\mathrm{~d},{ }^{3} \mathrm{~J}=8.4 \mathrm{~Hz}, 2 \mathrm{H}\right)$. M.p. $215-216^{\circ} \mathrm{C}$ (dec.).

(24) $N, N$-Bis(3-quinolinyl)-1,10-phenanthroline-2,9-

dicarboxamide (4). Under anhydrous conditions, 4dimethylaminopyridine (DMAP, $340 \mathrm{mg}, 2.8 \mathrm{mmol}, 2.5$ equiv), $\mathrm{N}$ (3-dimethylaminopropyl)- $N$ '-ethylcarbodiimide hydrochloride (EDC•HCl, $640 \mathrm{mg}, 3.4 \mathrm{mmol}, 3.0$ equiv.), and 3-aminoquinoline ( $450 \mathrm{mg}, 3.1 \mathrm{mmol}, 2.8$ equiv.) were added as solids to a suspension of compound 3 ( $3.0 \times 10^{2} \mathrm{mg}, 1.1 \mathrm{mmol}, 1.0$ equiv.) in DMF (23 mL). The solution was placed under argon and stirred at room temperature (48 hours). The resulting yellow suspension was filtered under vacuum and the isolated precipitate washed with saturated aqueous sodium bicarbonate $(30 \mathrm{~mL}), \mathrm{CH}_{2} \mathrm{Cl}_{2}(20$ $\mathrm{mL}$ ), and diethylether (20 mL) to afford pure compound 4 as a pale yellow solid (490 mg, 85\%). ${ }^{\mathbf{1}} \mathbf{H}$ NMR (300 MHz, DMSO-d 6 ) $\delta 7.68$ $(\mathrm{t}, 3 \mathrm{~J}=7 \mathrm{~Hz}, 2 \mathrm{H}), 7.75(\mathrm{t}, 3 \mathrm{~J}=7 \mathrm{~Hz}, 2 \mathrm{H}), 8.09-8.13(\mathrm{~m}, 4 \mathrm{H}), 8.33$ $(\mathrm{s}, 2 \mathrm{H}), 8.69\left(\mathrm{~d},{ }^{3} \mathrm{~J}=8 \mathrm{~Hz}, 2 \mathrm{H}\right), 8.91\left(\mathrm{~d},{ }^{3} \mathrm{~J}=8 \mathrm{~Hz}, 2 \mathrm{H}\right), 9.17\left(\mathrm{~d},{ }^{4} \mathrm{~J}=\right.$ $2 \mathrm{~Hz}, 2 \mathrm{H}$ ), 9.68 (d, ${ }^{4} \mathrm{~J}=2 \mathrm{~Hz}, 2 \mathrm{H}$ ), 11.88 (s, $2 \mathrm{H}$ ). M.p. > $280{ }^{\circ} \mathrm{C}$ (lit. $\left.>260{ }^{\circ} \mathrm{C}\right) .^{7}$

(25) $\mathbf{N}, \mathbf{N}$-Bis(3-[1-methylquinolinium])-1,10-phenanthroline-2,9dicarboxamide diiodide (5). Under anhydrous conditions and argon atmosphere, methyl iodide $(0.24 \mathrm{~mL}, 4.0 \mathrm{mmol}, 21$ equiv. was added dropwise to a solution of $4\left(1.0 \times 10^{2} \mathrm{mg}, 0.19 \mathrm{mmol}\right.$, 1.0 equiv.) in anhydrous DMF ( $4.5 \mathrm{~mL})$. The solution was protected from light, stirred and heated at $85{ }^{\circ} \mathrm{C}$ for 13 hours. The resulting suspension was filtered, and the isolated precipitate washed with diethylether to afford pure product as an iodide salt $(120 \mathrm{mg}$, 75\%). ${ }^{1} \mathbf{H}$ NMR (500 MHz, DMSO-d 6$) \delta 4.75(\mathrm{~s}, 6 \mathrm{H}), 8.09\left(\mathrm{t},{ }^{3} \mathrm{~J}=7.5\right.$ $\mathrm{Hz}, 2 \mathrm{H}), 8.26(\mathrm{t}, 3 \mathrm{~J}=7.5 \mathrm{~Hz}, 2 \mathrm{H}), 8.40(\mathrm{~s}, 2 \mathrm{H}), 8.54-8.57(2 \mathrm{~d}, 4$ H), $8.33(\mathrm{~s}, 2 \mathrm{H}), 8.77(\mathrm{~d}, 3 \mathrm{~J}=8.4 \mathrm{~Hz}, 2 \mathrm{H}), 8.99(\mathrm{~d}, 3 \mathrm{~J}=8.4 \mathrm{~Hz}, 2 \mathrm{H})$, 9.93 (s, $2 \mathrm{H}), 10.33$ (s, $2 \mathrm{H}), 12.17$ (s, $2 \mathrm{H})$.

(26) PhenDC3. Method 1. A solution of silver(I) triflate (13 mg, $5.1 \times 10$ ${ }^{5}$ mol, 2.2 equiv.) in methanol $(0.60 \mathrm{~mL})$ was added to a solution of 5 (19 mg, $2.4 \times 10^{-5}$ mol, 1.0 equiv.) in acetonitrile $(13 \mathrm{~mL})$ and methanol $(24 \mathrm{~mL})$. Immediate precipitation of a yellow solid was observed. The suspension was protected from light and left to stir at room temperature (30 $\mathrm{min})$, then filtered, and the filtrate concentrated under reduced pressure to afford Phen-DC3 as a pale yellow powder (20 mg, 99\%). Method 2. To a solution of $\mathbf{5}$ (28 $\mathrm{mg}, 3.5 \times 10^{-5} \mathrm{~mol}, 1.0$ equiv. $)$ in acetonitrile $(10 \mathrm{~mL})$ and methanol $(18 \mathrm{~mL})$ was added a solution of calcium(II) triflate $(71 \mathrm{mg}, 0.21$ mmol, 6.0 equiv.) in the same mix of acetonitrile/methanol (1.5 $\mathrm{mL}$ ). The solution was protected from light and stirred at room temperature ( $40 \mathrm{~min}$ ), then concentrated to dryness. MilliQ water (7 $\mathrm{mL}$ ) was added and the suspension filtered and washed with diethyl ether to obtain Phen-DC3 as a yellow powder $25 \mathrm{mg}$, 84\%). E. A. calc. for $\mathrm{C}_{36} \mathrm{H}_{26} \mathrm{~N}_{6} \mathrm{~F}_{6} \mathrm{O}_{8} \mathrm{~S}_{2} \cdot 2 \mathrm{H}_{2} \mathrm{O}: \% \mathrm{C} \mathrm{48.87,} \mathrm{\%} \mathrm{H} \mathrm{3.42,}$ \% N 9.50; found: \% C 49.23, \% H 3.72, \% N 9.57. Quantification by ${ }^{19} \mathrm{~F}$ NMR using a known volume of standard (trifluorotoluene) also confirmed that two equivalents of triflate were present in the product of each method. ${ }^{19} \mathbf{F}$ NMR $\left(500 \mathrm{MHz}\right.$, DMSO-d $_{6}+$ trifluorotoluene) $\delta-80.3$. 